Environmental Conservation (2016) 43 (2): 97-108 (C) Foundation for Environmental Conservation 2016. This is an Open Access article, distributed under the terms of the Creative Commons Attribution licence (http://creativecommons.org/licenses/by/4.0/), which permits unrestricted re-use, distribution, and reproduction in any medium, provided the original work is properly cited.

\title{
Antarctic geoconservation: a review of current systems and practices
}

\author{
KEVIN A. HUGHES ${ }^{1 *}$, JERÓNIMO LÓPEZ-MARTÍNEZ ${ }^{2}$, JANE E. FRANCIS ${ }^{1}$, \\ J. ALISTAIR CRAME ${ }^{1}$, LUIS CARCAVILLA ${ }^{3}$, KAZUYUKI SHIRAISHI ${ }^{4,5}$, \\ TOMOKAZU HOKADA ${ }^{4,5}$ AND AKIRA YAMAGUCHI ${ }^{4,5}$ \\ ${ }^{1}$ British Antarctic Survey, Natural Environment Research Council, High Cross, Madingley Road, Cambridge CB3 OET, UK, ${ }^{2}$ Universidad \\ Autónoma de Madrid, Facultad de Ciencias, Departamento de Geología y Geoquímica, 28049 Madrid, Spain, ${ }^{3}$ Geological Survey of Spain, Rios \\ Rosas, 23, 28003 Madrid, Spain, ${ }^{4}$ National Institute of Polar Research (NIPR), 10-3 Midori-cho, Tachikama-shi, Tokyo 190-8518, Japan, and \\ ${ }^{5}$ SOKENDAI (The Graduate University for Advanced Studies), 10-3 Midori-cho, Tachikama-shi, Tokyo 190-8518, Japan \\ Date submitted: 15 May 2015; Date accepted: 29 October 2015; First published online 9 February 2016
}

\section{SUMMARY}

The prohibition of commercial mineral resource extraction through the Antarctic Treaty System has removed one significant source of potential damage to Antarctica's geological and geomorphological values. However, given the on-going increase in Antarctic tourism and scientific footprint, some high-quality geological features may be vulnerable to human impact, such as damage due to the construction of logistical facilities, unregulated collection of geological specimens or oversampling for scientific purposes. The Protocol on Environmental Protection to the Antarctic Treaty puts in place a framework for the protection of Antarctica's environmental, scientific, historic, wilderness and aesthetic values. However, the Antarctic Protected Area system is still immature and further implementation of existing management tools may be required to protect the diverse range of vulnerabilities, qualities and spatial scales represented in the geology and geomorphology of the continent. At sites where high-quality mineralogical or palaeontological specimens exist in limited quantities, considerations of how best to prevent oversampling and manage access to remaining material may be supported by assessment of cumulative impacts. Examination of the level of Antarctic specimen loans from a selection of national geological collections suggested that existing publically accessible geological collections could be better utilized, which could reduce environmental impact and oversampling at vulnerable Antarctic sites.

Keymords: Antarctic Specially Protected Area, environmental impact assessment, fossils, geoconservation, geodiversity, geological collections, geological conservation, legislation, minerals, monitoring

\section{INTRODUCTION}

Antarctica's geodiversity is of fundamental importance to the environmental, scientific, wilderness and aesthetic values of

*Correspondence: Dr Kevin A. Hughes Tel: +44(0)1223 221616 e-mail:kehu@bas.ac.uk the continent, and the pursuit of geological knowledge has had a strong influence on its historical values (Fig. 1 and 2). For example, Captain Scott's doomed South Pole party of 1912 collected $16 \mathrm{~kg}$ of rocks including fossil leaves of Glossopteris indica, which provided evidence that Antarctica was once part of the larger supercontinent of Gondwana. The spectacular nature and aesthetic qualities of Antarctica can be attributed in part to the landforms and geology of the region's ice-free areas. However, the continent's scientific values are of primary importance and have provided knowledge on topics of global value, including plate tectonics and past climates. Therefore, it is essential that protection of Antarctica's geological features must accommodate access by scientists, application of research techniques and responsible removal of geological samples by researchers in the pursuit of scientific knowledge (Larwood \& King 2001).

Outside the Antarctic Treaty area, geological and geomorphological values can be protected under national legislation, often within parks or reserves, or their values may be recognized globally, for example, by designation as World Heritage Sites by the United Nations Educational, Scientific and Cultural Organisation (UNESCO), of which many examples exist around the world (Dingwall et al. 2005; Burek \& Prosser 2008). Geotourism (defined by Gray [2008] as 'tourism based on an area's geological or geomorphological resources that attempts to minimize the impact of this tourism through geoconservation management') is becoming more formally acknowledged as economically important in many parts of the world and UNESCO has also emphasized the importance of geoconservation and geodiversity through the Global Geoparks Network, which it officially recognized in December 2015. However, the consensus-driven multiParty governance of Antarctica means that these international initiatives are not considered suitable for use in the Antarctic region and so alternative management tools have been put in place through the Antarctic Treaty System.

Since the inception of the current Antarctic Protected Areas system in 2002, attention has been given by the Antarctic Treaty Parties predominantly to the protection of biological values, such as bird colonies and terrestrial biological communities (Shaw et al. 2014). By contrast, geodiversity (defined by Johannson [2000] as 'the complex variation of bedrock, unconsolidated deposits, landforms and processes that form landscapes. Geodiversity can be described as the 


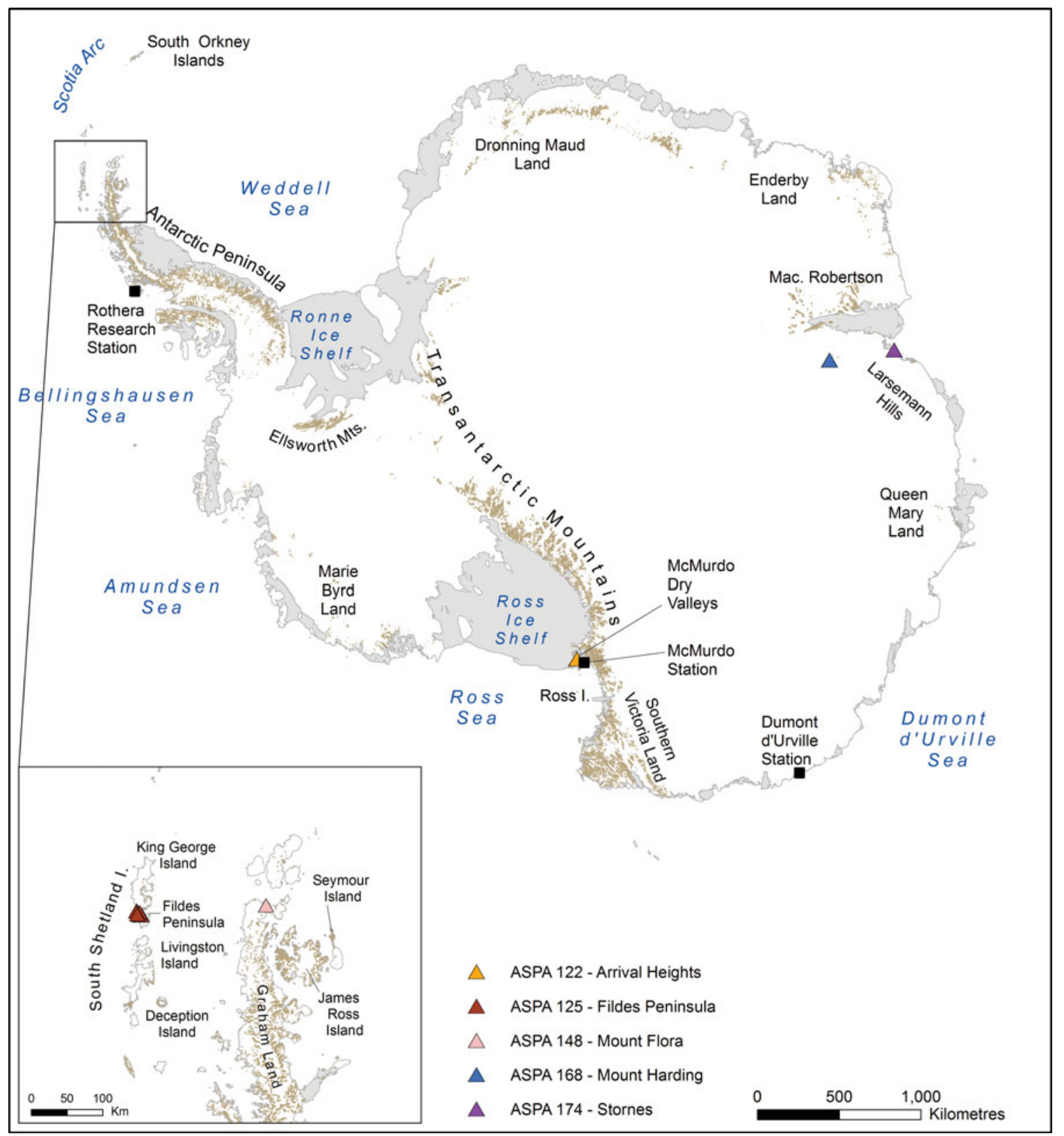

Figure 1 Map of Antarctica showing the location of sites and Antarctic Specially Protected Areas (ASPAs) mentioned in this paper.

diversity of geological and geomorphological phenomena in a defined area') and geoconservation (defined by Prosser [2013] as 'action taken with the intent of conserving and enhancing geological, geomorphological and soil features, processes, sites and specimens, including associated promotional and awareness raising activities and the recording and rescue of data or specimens from features and sites threatened with loss or damage') have received relatively little attention (UK et al. 2014). Within Antarctica, ice shelves, ice sheets and glaciers dominate the landscape and could be considered as a component of geodiversity, but as yet little specific provision has been made for their protection. This review aims to set out the current systems and practices for protection of geological and geomorphological values in Antarctica to better inform scientists, environmental managers and policy makers, including those within the Antarctic Treaty System, on issues that need, in some cases, urgent attention. Therefore the objectives of this review are to (i) set out the existing legal framework for protection of geodiversity in Antarctica; (ii) describe the threats to Antarctic geological and geomorphological values and how they may benefit from protection; (iii) discuss legal and management issues regarding the practical delivery of Antarctic geoconservation; (iv) examine the level of use by scientists of Antarctic rock, fossil, mineral and meteorite specimens in existing geological collections; and (v) make some initial recommendations on 

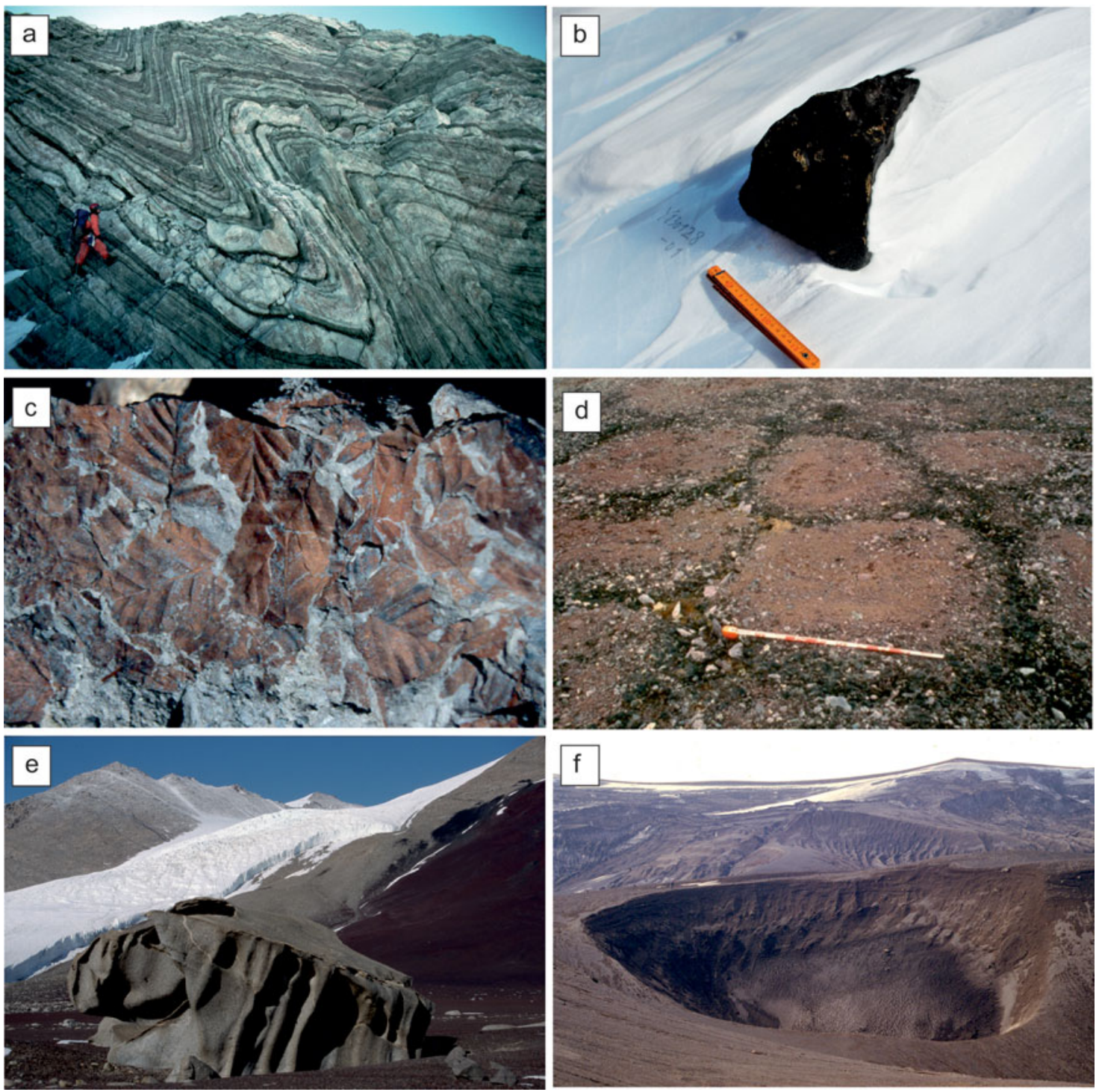

Figure 2 Examples of the diverse geological features found in Antarctica: (a) Permo-Triassic age folding of Palaeozoic quartzites, Heritage Range, Ellsworth Mountains (Photo: M. Curtis); (b) Meteorite Asuka 12389 (meteorite type: LL chondrite) taken in the field. (Photo: Japanese Antarctic Research Expedition (JARE) 54 - BELARE SAMBA research programme, 2012-2013); (c) fossil leaves of Nothofagus beardmorensis from the Sirius Group sediments, Oliver Bluffs, Transantarctic Mountains (Photo: J. Francis); (d) patterned ground on King George Island, South Shetland Islands (Photo: J. López-Martínez); (e) tafoni at Ventifact Knobs above Lake Bonney, McMurdo Dry Valleys, Victoria Land (Photo: D. Wynn-Williams); and ( $f$ ) crater formed by a recent eruption on Deception Island, South Shetland Islands (Photo: J. López-Martínez).

how protection and management of Antarctica's geological and geomorphological values might be improved.

\section{ANTARCTIC LEGISLATIVE FRAMEWORK}

The Antarctic Treaty (signed 1959, entered into force 1961) is the legal instrument by which the Antarctic Treaty area (which is defined as the area south of latitude $60^{\circ} \mathrm{S}$ ) is governed (Fig. 3). Currently signed by 53 Parties representing $c .65 \%$ of the world's population (Table 1), the Treaty, amongst other things, prohibits nuclear testing and military activities and puts into abeyance all territorial claims, but says little about environmental protection, including protection of geological and geomorphological values. However, protection and conservation within the Treaty area is achieved through the Protocol on Environmental Protection to the Antarctic Treaty (also known as the Madrid Protocol or the Environmental Protocol; agreed in 1991, entered into force in 1998 and currently adopted by 37 countries). The Environmental Protocol (Article 7) states that 'any activity relating to mineral resources, other than scientific research, shall be prohibited'. This prohibition of the commercial exploitation of mineral resources, that is, mining, removes one significant source 
Table 1 Parties that are signatories to the Antarctic Treaty (1959) and Protocol on Environmental Protection to the Antarctic Treaty (1991). * Indicates that the Party is a signatory to the Protocol on Environmental Protection to the Antarctic Treaty. All Consultative Parties are signatories to the Protocol.

\begin{tabular}{lc}
\hline \hline $\begin{array}{l}\text { Consultative Parties to the Antarctic Treaty (attend Treaty } \\
\text { Meetings and are involved in decision-making) }\end{array}$ & $\begin{array}{l}\text { Non-consultative Parties to the Antarctic Treaty (attend Treaty } \\
\text { Meetings but are not involved in decision-making) }\end{array}$ \\
\hline Australia*, Argentina*, Belgium*, Brazil*, Bulgaria*, Chile*, & Austria, Belarus*, Canada*, Columbia, Cuba, Denmark, Estonia, \\
China*, Czech Republic*, Ecuador*, Finland*, France*, $^{*}{ }^{*}$, Greece*, Guatemala, Hungary, Iceland, Kazakhstan, North \\
Germany*, India*, Italy*, Japan*, South Korea*, the & Korea, Malaysia, Monaco*, Mongolia, Pakistan*, Papua New \\
Netherlands*, New Zealand*, Norway*, Peru*, Poland*, Russian & Guinea, Portugal*, Romania*, Slovak Republic, Switzerland, \\
Federation*, South Africa*, Spain*, Sweden*, Ukraine*, UK*, & Turkey, Venezuela* \\
USA*, Uruguay* $^{*}$ & \\
\hline \hline
\end{tabular}

Figure 3 Legislative framework that facilitates protection of geodiversity within the Antarctic Treaty area. Bolding shows the piece of legislation that refers to protection of geological features.

\begin{tabular}{|c|c|c|c|c|c|}
\hline & & \multicolumn{2}{|c|}{ Antarctic Treaty } & & \\
\hline & & \multicolumn{2}{|c|}{$\downarrow$} & & \\
\hline \multicolumn{6}{|c|}{ Protocol on Environmental Protection to the Antarctic Treaty } \\
\hline $\begin{array}{l}\text { Annex I: } \\
\text { Environmental } \\
\text { Impact } \\
\text { Assessment }\end{array}$ & $\begin{array}{l}\text { Annex II: } \\
\text { Conservation } \\
\text { of Fauna and } \\
\text { Flora }\end{array}$ & $\begin{array}{l}\text { Annex III: } \\
\text { Waste Disposal } \\
\text { and Waste } \\
\text { Management }\end{array}$ & \begin{tabular}{|l|} 
Annex IV: \\
Prevention \\
of Marine \\
Pollution
\end{tabular} & \begin{tabular}{|l|} 
Annex V: \\
Area \\
Protection and \\
Management
\end{tabular} & \begin{tabular}{|l|} 
Annex VI: \\
Liability Arising \\
from Environmental \\
Emergencies
\end{tabular} \\
\hline \multicolumn{6}{|c|}{$\sqrt{6}$} \\
\hline \multicolumn{3}{|c|}{ Antarctic Specially Protected Areas (ASPAs) } & \multicolumn{3}{|c|}{ Antarctic Specially Managed Areas (ASMAs) } \\
\hline \multicolumn{6}{|c|}{$\downarrow$} \\
\hline \multicolumn{6}{|c|}{$\begin{array}{l}\text { Areas to be protected as ASPAs: } \\
\text { (a) inviolate areas } \\
\text { (b) areas with representative examples of ecosystems } \\
\text { (c) areas with important or unusual assemblages of species } \\
\text { (d) the type locality or only known habitat of any species } \\
\text { (e) areas for on-going or planned scientific research } \\
\text { (f) examples of outstanding geological, glaciological or geomorphological features } \\
\text { (g) areas with outstanding aesthetic and wilderness value } \\
\text { (h) sites or monuments of historic value }\end{array}$} \\
\hline
\end{tabular}

of human impact and destruction of geological features currently occurring in other areas of the world. Article 7 of the Environmental Protocol is therefore probably the most important legislation for geoconservation, albeit that this may not have been its primary aim.

The Protocol has an indefinite duration, but Article 25 does provide for a review process 50 years after the Protocol entered into force (a review can take place in 2048). Modifications may then be made, but only with the agreement of a threequarter majority of the nations that were Antarctic Treaty Consultative Parties when the Protocol was adopted in 1991 (that means 26 Parties must agree). One further important factor is that the prohibition on exploitation of mineral resources may only be amended if a binding legal regime is in force on future Antarctic mineral resource activities. The regime must include an agreed means for determining whether any such mineral resource activities would be acceptable and, if so, under what conditions. Furthermore, the development of such a regime must protect the interests of Antarctic claimant states (Article 25, para. 5(a)) and would require the agreement of all Antarctic Treaty Consultative Parties.
The Environmental Protocol also contains six Annexes with some of particular relevance to geoconservation (Fig. 3 and Table 2). Annex I to the Protocol sets out the requirement that all planned activities performed in the Treaty area that will have an impact equal to or greater than 'minor or transitory' must undergo an environmental impact assessment (EIA). If the likely level of impact is considered to be equal to 'minor or transitory' then an Initial Environmental Evaluation is required, while for impacts greater than 'minor or transitory' a Comprehensive Environmental Evaluation is required. The Annex does not define the term 'minor or transitory' and Parties have agreed that the interpretation of this term will need to be made on a case by case site specific basis, due to the number of variables associated with each activity and each environmental context. Nevertheless, despite the guidance provided in 'Guidelines for Environmental Assessment in Antarctica' (Antarctic Treaty Consultative Meeting 2005), the interpretation of the term differs markedly between Parties. For example, the environmental impacts of quarrying activities on Fildes Peninsula, King George Island, covering an area of $c .60000 \mathrm{~m}^{2}$ between 2008 and 2011 (Braun et al. 
Table 2 Summary of the Annexes to the Protocol on Environmental Protection to the Antarctic Treaty.

\begin{tabular}{|c|c|c|}
\hline Annex & Title & Major role \\
\hline I & Environmental Impact Assessment & $\begin{array}{l}\text { Details the need for prior assessment of the likely impacts of activities } \\
\text { on the Antarctic environment }\end{array}$ \\
\hline II & Conservation of Antarctic Fauna and Flora & $\begin{array}{l}\text { Details the protection of Antarctic plants and animals and restrictions } \\
\text { on non-native species introductions }\end{array}$ \\
\hline III & Waste Disposal and Waste Management & $\begin{array}{l}\text { Encourages the reduction of waste generation, specifies wastes that } \\
\text { should be removed from Antarctica, prohibits open burning of waste } \\
\text { and disposal on land and in the sea and restricts importation of } \\
\text { potentially polluting materials }\end{array}$ \\
\hline IV & Prevention of Marine Pollution & $\begin{array}{l}\text { Prohibits the discharge of certain materials into the sea by ships } \\
\text { operating in Antarctica }\end{array}$ \\
\hline $\mathrm{V}$ & Area Protection and Management & $\begin{array}{l}\text { Regulates the protection and management of Antarctic Specially } \\
\text { Protected Areas, Antarctic Specially Managed Areas and Historic } \\
\text { Sites and Monuments }\end{array}$ \\
\hline VI & Liability Arising from Environmental Emergencies & $\begin{array}{l}\text { Describes procedures relating to liability for environmental damage in } \\
\text { Antarctica (not yet entered into force) }\end{array}$ \\
\hline
\end{tabular}

2014) and projects involving blasting or cutting of up to $c$. $4500 \mathrm{~m}^{3}$ of rock (c. 13500 tons) for roadways near Indian and Italian research stations (India 2010; Italy 2014) have been considered by those Parties to be no greater than 'minor or transitory'. Therefore, in these examples, Comprehensive Environmental Evaluations were not undertaken and, as a consequence, little consultation was made with other Treaty Parties. Such activities are not new to Antarctica, and prior to the implementation of the Environmental Protocol and mandatory EIAs, rock blasting also occurred in the construction of the runways at Rothera Research Station (UK, for EIA; NERC 1989) and Dumont d'Urville Station (France) and extensive landscaping has occurred at McMurdo Station (US; Kennicutt et al. 2010) (Fig. 1).

\section{Development and implementation of the Antarctic Protected Area system}

During the development of the Antarctic Protected Area system over the past 50 years, the protection of specific geological features and values has not featured as prominently as the protection of biological values, despite their close association. In the preamble to Recommendation ATCM VII-3 (agreed in Wellington 1972) it was made clear that areas of non-biological interest could not be designated as Specially Protected Areas (SPAs), which, in effect, excluded areas of primarily geological value from enhanced protection. Following a proposal by the Scientific Committee on Antarctic Research (SCAR), a new category of protected area called a Site of Special Scientific Interest (SSSI) was created at ATCM VIII (agreed in Oslo 1975; Recommendation ATCM VIII-3), which protected areas where scientific investigations, including geological research, were undertaken or were planned to be undertaken in the future. Further attempts were made to enhance geoconservation when, in 1989, an additional category of protected area known as a Special Reserved Area (SRA) was proposed to protect outstanding geological, glaciological, geomorphological, aesthetic, scenic or wilderness values (agreed in Paris 1989; Recommendation ATCM XV-10); however, SRAs were never formally adopted.

The entry into force of Annex V (Area Protection and Management) to the Environmental Protocol in 2002 facilitated a restructuring of the Antarctic Protected Area system, with the re-designation of existing SPAs and SSSIs as Antarctic Specially Protected Areas (ASPAs). All ASPAs must have a management plan and entry to the 72 ASPAs that exist currently is only permitted in accordance with a permit issued by an appropriate national authority (usually a government agency). Annex V states that 'Parties shall seek to identify, within a systematic environmental-geographical framework, and to include in the series of Antarctic Specially Protected Areas...examples of outstanding geological, glaciological or geomorphological features' (Article 3, para. 2(f)). ASPAs must have an accompanying management plan that describes the primary value protected within the area and sets out practical management measures to afford adequate protection. In recent years there has been some progress in the development of a systematic environmental-geographical framework for the protection of values within Antarctica. In Resolution 3 (agreed in Kiev 2008) the Parties recommended that the Environmental Domains Analysis for the Antarctic Continent (EDA) be used 'consistently and in conjunction with other tools agreed within the Antarctic Treaty System as a dynamic model for the identification of areas that could be designated as Antarctic Specially Protected Areas within the systematic environmental-geographical framework referred to in Article 3(2) of Annex V of the Protocol'. In Resolution 6 (agreed in Hobart 2012) the Parties agreed that the Antarctic Conservation Biogeographic Regions (ACBRs) should be used in a similar fashion. The EDA used available climate, slope, land cover and geological data to divide the continent into 21 separate Environmental Domains, but this framework was of limited use for identifying geodiversity. The ACBRs build on the EDA and comprise 15 biologically distinct ice-free regions, 
based on the distribution of the best available biodiversity data. While the EDA and ACBRs provide useful frameworks for the protection of biological values, due to the nature of the data involved in these classifications, they are of limited value for identifying outstanding geological and geomorphological values.

Annex V also created a new category of protected area known as an Antarctic Specially Managed Area (ASMA) the aim of which was to 'assist in the planning and coordination of activities, avoid possible conflicts, improve co-operation between Parties or minimize environmental impacts'. Entry into the six ASMAs that currently exist does not require a permit, but an ASMA may be divided into zones such as Scientific Zones (protecting scientific research activities, including geological research), or Restricted Zones that may be used to limit access to an area, including those containing vulnerable geological or geomorphological features (e.g. ASMA 2 McMurdo Dry Valleys, Southern Victoria Land).

Although not mentioned within the Environmental Protocol, the Treaty Parties agreed that Site Guidelines for Visitors (SGVs) should be prepared for the most commonly visited locations in Antarctica and 37 such areas now have guidelines (see Resolution 3; agreed in Brussels, 2013). The guidelines were devised primarily to help manage visits by the tourism industry, but they apply to all visitors including the personnel of national operators. The guidelines are not legally binding but may act as a useful management tool to prevent access or damage to vulnerable geological features through the informal designation of 'Closed Areas'.

The Antarctic Treaty Consultative Meeting has, in addition to legislation and various management tools, agreed Resolution 3 (agreed in St. Petersburg 2001), Collection of Meteorites in Antarctica, which urges Parties 'to take such legal or administrative steps as are necessary to preserve Antarctic meteorites so that they are collected and curated according to accepted scientific standards, and are made available for scientific purposes'.

\section{ANTARCTIC GEODIVERSITY: THREATS AND PROTECTION}

\section{Potential threats to geodiversity in Antarctica}

Antarctica has no indigenous population and few visitors land in Antarctica each year compared to other parts of the world (up to $c .37000$ tourists and $c .4000$ science and support personnel visit each year). This would appear to be a small number of people, given the vastness of Antarctica ( $c$. $14000000 \mathrm{~km}^{2}$ ), until we remember that only $c .0 .3 \%$ of the continent is ice-free $\left(c .44000 \mathrm{~km}^{2}\right)$. Furthermore, much of the human activity in Antarctica is limited to a small number of locations, predominantly coastal, which are accessible by ship and thereby facilitate visitation by tourists and/or the establishment and maintenance of research stations by national operators (Tin et al. 2009).
Potential threats to geological features of environmental or scientific value might include oversampling of rare rocks, fossils and minerals for scientific purposes. For example, rock outcrops at Stornes, Larsemann Hills, contain an unusually diverse selection of phosphate and borosilicate minerals, and are the type localities for three new mineral species (the boron mineral boralsilite and the phosphate minerals stornesite-[yttrium] and tassieite) (Grew \& Carson 2007; Norway $2014 a$ ). Yet these minerals, which may not be found in other locations in such a spectacular form, are vulnerable to oversampling. The same is almost certainly true for fossils, with those occurring at various localities in the Scotia Arc and Antarctic Peninsula region being particularly at risk (Fig. 1). King George Island and Livingston Island (South Shetland Islands), which contain ASPAs protecting geological and geomorphological values, are visited frequently by both scientific and tourist parties, but perhaps the area most at risk from poorly regulated collecting is the James Ross Island group where no formal geoconservation measures have been implemented, despite it being one of the most important fossil localities in Antarctica (see below). More broadly, increases in the number of nations operating in Antarctica, sometimes in areas where the research stations of other Parties are already in place, may lead to duplicate sampling of geological specimens to supply national geological collections.

Rocks, meteorites, minerals and fossils may be vulnerable to unauthorised collection by tourists and national operator staff. The collection and transportation of fossils out of Antarctica has been a topic of recent discussion within the Antarctic Treaty Consultative Meeting's (ATCM) Committee for Environmental Protection (CEP), with calls for better cooperation from within the tourism industry to prevent unregulated removal of geological samples (Argentina 2014). Highlighting this issue, it is possible to find Antarctic mineral and rock specimens occasionally marketed for sale on the internet (for example, rock samples from the Antarctic Peninsula area were advertised for sale on the website eBay in March 2014).

Inadvertent damage may be done to the scientific values of a location by movement of rocks and fossils out of their stratigraphical context; for example, the movement of a surface fossil from one location to another may give false information of the presence of that fossil species in the geological record and even of the age of the stratigraphic record. Sites with large exposures of fossil beds may be particularly vulnerable to this threat; for example, the extensive Cretaceous-early Cenozoic succession within the James Ross Island Group, which is over $6 \mathrm{~km}$ thick. This region is now subject to guided walks for tourists, who may not be fully aware of the consequences to science of inadvertently moving rock and fossil material from one locality to another. Furthermore, the movement of surface rocks and boulders may make them no longer useful for cosmogenic analysis (Cockburn \& Summerfield 2004). This technique is of particular use for estimating past ice sheet thickness and extent in areas such as the Antarctic Peninsula and the Ellsworth Mountains, yet it is here that tourism 


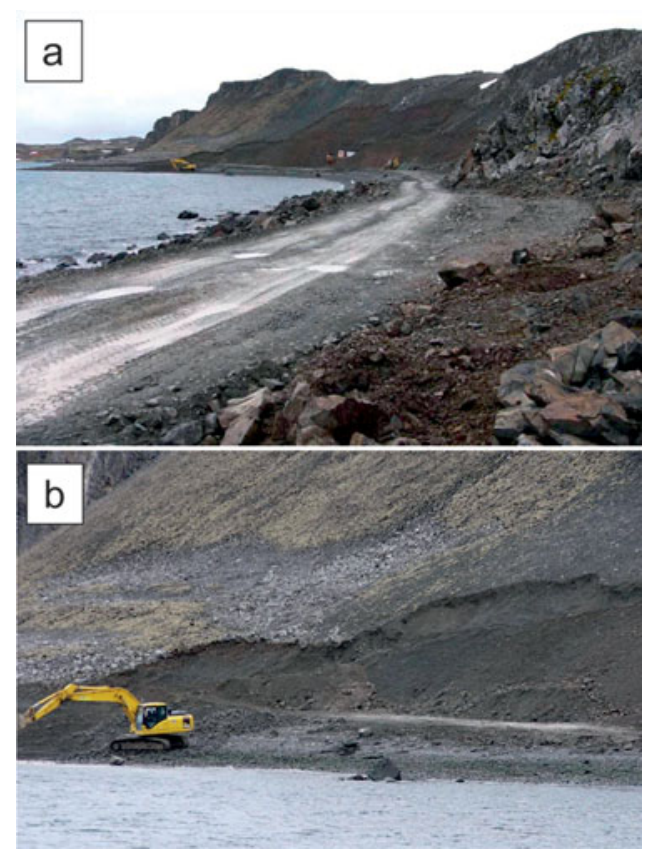

Figure 4 (a) Access road to Quarry No. 3, Fildes Peninsula, King George Island (Photo: H.-U. Peter); and (b) extraction of material within part of Quarry No. 3 (Photo: H.-U. Peter).

activities, such as scenic walks and the ascent of some of Antarctica's highest mountains, are growing and may increase in spatial extent (Glasser et al. 2014).

Geodiversity may be impacted by the construction of research stations or other facilities, either through the blasting/quarrying of rocks to provide aggregate for construction purposes or creation of cuttings for roads, or simply by obscuring geological features beneath station buildings (Fig. 4). Geomorphological features (including patterned ground, polygons and stone strips; Fig. $2 d$ ) in particular may be vulnerable to damage by construction projects. For example, many coastal research stations in the Antarctic Peninsula region are constructed on raised beaches, which in some locations have been damaged irreversibly by quarrying activities (Fretwell et al. 2010; Braun et al. 2014).

\section{What types of geological and geomorphological elements may benefit from protection?}

It is clear that geological features are an integral component of the Antarctic landscape and to some extent informed judgements will need to be made regarding the value and appropriate level of protection of individual features. For example, some features, including those of a large scale, may be highly resistant to any conceivable human impact, including station construction or oversampling. While station construction may conceal one part of a feature, sites of equal or better scientific value may be located in the vicinity. Furthermore, removal of samples may simply reveal further material beneath. Issues may arise when features are more delicate or scarce. In effect, key geological outcrops, rare minerals, fossils, meteorites and many geomorphological features are a non-renewable resource and all activities and sampling undertaken should consider, ideally, the impact on the availability of high-quality material and features for future earth science. Geodiversity worthy of protection might include:

- Outcrops containing rare or unique minerals (e.g. rare boron and phosphate minerals in ASPA 174 Stornes, Larsemann Hills, Princess Elizabeth Land; Grew et al. 2006; Fig. 1).

- Areas of blue ice where concentrations of meteorites are found (Folco et al. 2002; Harvey 2003).

- Ice-free areas or blue ice moraines of use for cosmogenic analysis dating (Kong et al. 2010; Fogwill et al. 2012).

- Rare, unique or vulnerable glacial and/or geomorphological features (such as protected within ASPA 168 Mount Harding; Fang et al. 2004; Gillies et al. 2009; Fig. 1).

- Representative sections of unique or particularly wellexposed stratigraphy (e.g. the Cretaceous-Paleogene boundary located within the James Ross Island group; Crame et al. 2004; Bowman et al. 2012; Fig. 1).

- Unique or exceptional examples of rock structures (e.g. unconformities, folds, faults and intrusions; Fig. 2).

- Locations where rare or unique fossils (including trace fossils) and fossil beds are found (e.g. ASPA 148 Mt Flora and ASPA 125 Fildes Peninsula; Francis et al. 2006; Fig. 1 and 2).

- The 'type locality' for a rock type, stratigraphic unit, fossil or mineral (Grew et al. 2006; Grew \& Carson 2007).

- Patterned ground and soils of particular value, which may be vulnerable to relatively low levels of human impacts, including trampling (e.g. protected as a secondary value within ASPA 122 Arrival Heights, Hut Point Peninsula, Ross Island; Fig. 1).

\section{ANTARCTIC GEOCONSERVATION: ISSUES AND POSSIBLE NEXT STEPS}

\section{Criteria for selecting areas worthy of protection}

Review of the tools used for geoconservation suggests a lack of solid criteria indicating why features have been selected for protection, rather than similar features in the local vicinity. The 'Guidelines for implementation of the Framework for Protected Areas set forth in Article 3, Annex V of the Environmental Protocol' (agreed through Resolution 1, The Hague 2000; Antarctic Treaty Consultative Meeting 2000) set out general guidelines for establishing the protection potential of an area and the 'quality' of the area's features. Geological, glaciological or geomorphological features should have 'distinctive or special characteristics of the history, structure or components of the Earth's crust, rocks, fossils and cryosphere or a result of present or past processes beneath or at the Earth's surface in Antarctica'. Quality criteria relevant to geological features include (i) representativeness; (ii) diversity; (iii) distinctiveness; (iv) degree of interference; and (v) scientific and monitoring uses, while vulnerability to 
environmental risks, including human activities and impacts, should also be taken into consideration. However, often due to time constraints, the match of a potential ASPA's features and values against these criteria is not always fully discussed when CEP are asked to recommend ASPA designation to the ATCM (Norway $2014 b$ ). This may be particularly true when geological values are not the primary reason for an area's proposed protection, as occurs in the majority of cases. In such cases, it is possible that geological and geomorphological elements may have been added by the proponent Party to the list of values to be protected to strengthen the case for protected area status. Consequently, the features listed may not be 'outstanding' (as mentioned in the Environmental Protocol) and on their own would not merit ASPA status. This potentially reduces the number of areas considered to contain truly 'outstanding' geological and geomorphological values by the proponents Parties and CEP.

\section{A systematic environmental-geographical framework for geoconservation - an achievable goal?}

Overall, examination of the use of management tools for geoconservation points to an unsystematic and, as yet, immature protection of Antarctic geological values (UK et al. 2014). Nevertheless, the requirement within Annex $\mathrm{V}$ to designate ASPAs to protect geological and geomorphological values within a systematic environmentalgeographical framework may not be a simple undertaking, due to the wide range of geological and geomorphological features distributed across the ice-free areas of Antarctica, and also within the marine environment. In addition, the current protected area management tools may not be adequately flexible to accommodate the diverse range of geological and geomorphological features that require some degree of protection. The requirement for a permit to access ASPAs may make ASPA designation for some 'robust' geological and geomorphological features seem a step too far, while ASMAs and SGVs may simply not be appropriate tools outside areas of high human activity. ASPA status should be reserved for areas of the most outstanding scientific or environmental value, or at sites where oversampling is a concern, while Restricted Zones within ASMAs have proven useful in areas where high levels of human visitation are possible. However, it is not clear how existing tools could be used to protect geological and geomorphological features of an important but less outstanding nature or those of a larger spatial scale.

\section{Cumulative environmental impacts}

According to Annex I to the Environmental Protocol, Parties must also consider cumulative environmental impact resulting from their activities. However, it is often difficult to ascertain levels of earlier geological sampling, potentially undertaken by researchers from different nations and particularly at more spatially restricted sites. For example, samples collected within ASPAs should be reported to the proponent Party using the 'Antarctic Specially Protected Area visitor report form' (Antarctic Treaty Consultative Meeting 2011), but there is little evidence that this reporting mechanism is widely used (Hughes et al. 2013; Pertierra \& Hughes 2013). Furthermore, little, if any, monitoring of the impact in situ of geological sample collection is undertaken, making it difficult to measure how much cumulative impact may have occurred. These issues are not unique to Antarctic geoconservation (JNCC 1997; Ellis et al. 1996; Prosser et al. 2006; Houshold \& Sharples 2008; Prosser 2013) and may benefit from further consideration by the Antarctic geological community, including input from SCAR through the Action Group on Geological Heritage and Geoconservation. An additional factor worth consideration is the potential impact of climate change on geodiversity and the associated opportunities for geoconservation (Prosser et al. 2010).

\section{USE OF GEOLOGICAL COLLECTIONS BY THE INTERNATIONAL SCIENCE COMMUNITY: CASE STUDIES}

Use of geological material in existing collections, rather than assembling new collections, should reduce the sampling pressure on vulnerable or spatially limited geological locations. Large, well-curated geological collections do exist, such as those of the US Polar Rock Repository, Byrd Polar Research Center; Paleontological Research Institution, Ithaca (USA); the British Antarctic Survey (BAS); and the National Institute of Polar Research of Japan (NIPR). Access to most geological collections is readily available. For example, the US Polar Rock Repository at the Byrd Polar Research Centre (Ohio, USA) offers in situ examination and loans of its samples to researchers, educators and museums. The collection database can be accessed online and any sample requests may also be submitted online. While marine geological core samples are available in many of the larger collections, repositories specialising in Antarctic marine geological core samples also exist. For example, the US Antarctic Research Facility at Florida State University houses over $20000 \mathrm{~m}$ of Antarctic and sub-Antarctic marine geological core samples and $3000 \mathrm{~m}$ of rotary cored geological material. Similarly, ice core collection repositories may make samples available for collaborative research (e.g. the US National Ice Cores Laboratory [NICL]).

Although large Antarctic geological collections may be available for research and educational purposes, little evidence is available to show how well geological material already collected within geological specimen depositories and collections is used by the international geological community. We attempt to provide relevant evidence in the following examples (see also Fig. 5).

\section{Case study 1. British Antarctic Survey Geological Collection}

The BAS Geological Collection is one of the largest in existence, containing over 150000 specimens, collected 


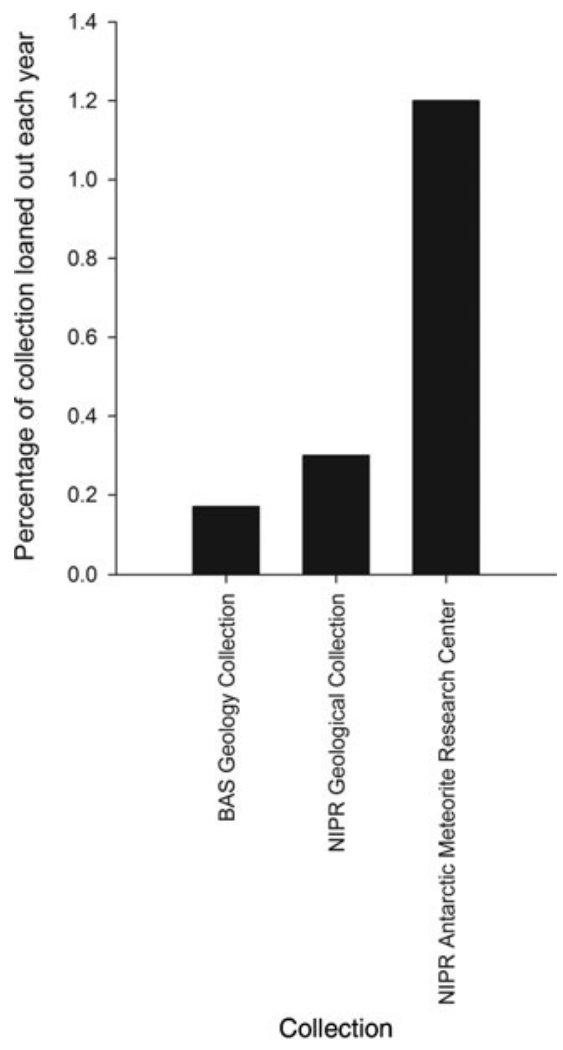

Figure 5 Mean percentage of specimens within geological collections loaned to national and international researchers each year (2009-2013). Data for the US Antarctic Meteorite Collection are not directly comparable with results from other collections and are not shown. BAS $=$ British Antarctic Survey; NIPR $=$ National Institute of Polar Research of Japan.

primarily from Antarctica and the sub-Antarctic islands over the past 60 years. Samples are available for loan to recognized institutions, and scientists are encouraged to visit BAS to use the specimens and the associated supporting information and resources. There is a wide range of samples collected for a variety of geological disciplines such as petrology, mineralogy, sedimentology and palaeontology. Preparations derived from the source material such as thin sections $(c .40000)$ and crushed products (c. 25000$)$ are also held. The location, field identification details and any analysis data for all the specimens are maintained within the BAS Geological Database. There are also archival items including field notebooks and maps that relate to individual specimens and the 'Type and Figured' fossil collection contains specimens that have been formally described or figured in scientific literature.

Country of origin of visitors to the BAS Geology Collection for the period 2009-2013 was examined, and it was revealed that scientists using the collection were predominantly from UK universities and institutes. Each year international scientists from between three and five other nations visited the collection for research purposes. During the same fiveyear period the number of new geological sample loans to non-UK institutes was recorded, with new loans made to a maximum of four institutes located outside the UK in any year. During the years 2009-2013, 1200 samples were lent to institutes in the UK and other countries, representing $c$. $0.8 \%$ of the total number of specimens in the collection (and equivalent to $c .0 .17 \%$ of the collection per year), with a small proportion of these samples being sent outside the UK.

\section{Case study 2. National Institute of Polar Research Geological Collection, Japan}

In Japan, specimens of rocks and minerals have been collected since the 1957/1958 International Geophysical Year by c. 100 geologists from c. 20 universities and research institutes that have participated in the Japanese Antarctic Research Expedition (JARE). Approximately 18000 of the aforementioned specimens are in the collection of the NIPR but specimens are also stored in university museums for display and research purposes, or are held by researchers in universities. Between the years 2009 and 2013 the NIPR loaned c. 250 rocks and mineral samples for research purposes $(<1.5 \%)$, with annual figures of between nine and 154 samples. The majority were loaned to national researchers and institutions. During the same period, between 33 and 78 samples by year were loaned for public display and education proposes, with a total of 229 samples loaned during the period 2009-2013.

\section{Case study 3. National Institute of Polar Research Antarctic Meteorite Research Center, Japan}

The Antarctic Meteorite Research Center of the NIPR maintains a collection of c. 17400 Antarctic meteorites (including unclassified meteorites), which started in 1969 following the first discovery of the Yamoto meteorites (Yoshida 2010). Allocation of collected meteorites is based on the evaluation of the proposals by the curators and Antarctic meteorite committee. During the period 2009-2013 between 20 and 50 proposals were received per year, and a total of 1068 meteorite samples loaned for research purposes (between 81 and 326 by year) equating to, on average, c. $1.2 \%$ of the meteorite collection being loaned out per year. During the same period, 584 meteorite samples (between 77 and 176 by year) were loaned to museums for public display, lectures and education proposes. A box containing thin sections of 30 typical meteorites was prepared and loaned for university education purposes. The thin section box was loaned 58 times during the period 2009-2013 (between 10 and 13 times by year).

\section{Case study 4. US Antarctic Meteorite Collection}

Another important reference collection is the US Antarctic Meteorite Collection (USANTMET), a joint effort by the Smithsonian Institution (Washington, D.C., USA) and the NASA Johnson Space Centre (Houston, Texas, USA). The USANTMET collection contains a total of $c .20000$ meteorite samples collected in the past 30 years, with $c .17000$ samples 
having been sent to scientists in the US and elsewhere during that time (equating to $c .2 .8 \%$ of the collection being loaned out per year; Righter et al. 2014).

\section{Overview of geological collection use}

Our analysis showed that, in general, the Antarctic geological collections are used most extensively by geologists from the same institution and country where the collection is located. Given the scale and breadth of the existing geological collections, the level of use by international scientists was not high (Fig. 5). Geologists may have sound scientific reasons for wanting to collect geological specimens from Antarctica in person. The orientation and spatial context of samples is crucial for many types of geological research, including tectonics, petrology, geochemistry, biostratigraphy and palaeobiology. In addition, geologists may not be entirely confident with the accuracy of the information accompanying samples within geological collections. Promoting the use of existing collections might lead to environmental and financial benefits if this reduces the need for costly Antarctic field work. Increased use of geological collections might be encouraged through more use of online technology. For example, 2000 fossil specimens held at BAS have had images plus associated taxonomic and bibliographic details made available for viewing online. Similarly, the Zinsmeister Antarctic Fossil Collection at the Paleontological Research Institution in Ithaca, New York, contains approximately 22000 specimens of Cretaceous-Eocene fossil molluscs from Seymour Island and the Antarctic Peninsula (Fig. 1) and recent digitization of the collection facilitates access to this important resource for research. If the availability of samples collected within Antarctica is a concern of the Treaty Parties, improvements could be made in the recording, tracking and dissemination of information on the range and location of samples collected.

\section{CONCLUDING REMARKS}

The Antarctic Treaty Consultative Parties have put in place legislation and developed several tools to protect values within Antarctica. However, overall, the Antarctic Protected Areas system is still immature relative to some other areas of the world (Shaw et al. 2014), but increasing levels of human activity and the growing footprint in the region make it essential that progress is made in area protection if values are not to be impacted or eroded over time (Hughes et al. 2011). Although geological and geomorphological values are protected to some degree, they have not yet received substantial attention by policy makers and scientists interested in geoconservation. Steps may be required to assess Antarctica's geodiversity more widely (and if feasible, within a systematic environmental-geographical framework, as described in the Environmental Protocol) with a view to affording protection, of an appropriate kind, to exceptional examples of minerals, fossils, meteorites, geomorphological features, stratigraphic series and other rock structures (Burek \& Prosser 2008; Larwood et al. 2013; Prosser 2013). However, it is imperative that this process does not prevent adequate access for novel scientific investigations that have undergone an appropriate level of EIA. In order to protect the continent's non-renewable geological specimens for future scientific studies, consideration should be given to (i) the criteria for geoconservation; (ii) improved recording and sharing of information on geological material that has been sampled; (iii) greater use of specimens in existing geological collections, where appropriate; and (iv) better monitoring of sampling impact at vulnerable sites to inform environmental management decisions.

\section{ACKNOWLEDGEMENTS}

This paper contributes to the British Antarctic Survey Polar Science for Planet Earth (PSPE) Biodiversity, Evolution and Adaptation (BEA) programme and the Environment Office Long Term Monitoring and Survey (EO-LTMS) project, and to the project CTM2014-57119-R of the Spanish R\&D National Plan. Oliva Martín-Sánchez is thanked for map preparation, and Alexander Tate and Hilary Blagbrough for providing information on the BAS Geological Collection. We also thank three anonymous reviewers for their insightful comments.

\section{References}

Antarctic Treaty Consultative Meeting (2005) Guidelines for Environmental Assessment in Antarctica. [www] document. URL http://www.ats.aq/documents/recatt/Att266_e.pdf

Antarctic Treaty Consultative Meetingy (2000) Guidelines for implementation of the Framework for Protected Areas set forth in Article 3, Annex V of the Environmental Protocol. [www] document. URL http://www.ats.aq/documents/recatt/Att081_e.pdf

Antarctic Treaty Consultative Meeting (2011) Antarctic Specially Protected Area visitor report form (Appendix 2 of the Guide to the preparation of management plans for Antarctic Specially Protected Areas). [www] document. URL http://www.ats.aq/ documents/recatt/Att477_e.pdf

Argentina (2014) Contributions to the protection of fossils in Antarctica. Working Paper 57. Antarctic Treaty Consultative Meeting XXXVII, Brasilia, Brazil, 28 April-7 May 2014.

Bowman, V.C., Francis, J.E., Riding, J.B., Hunter, S.J. \& Haywood, A.M. (2012) A latest Cretaceous to earliest Paleogene dinoflagellate cyst zonation from Antarctica, and implications for phytoprovincialism in the high southern latitudes. Reviem of Palaeobotany and Palynology 171: 40-56.

Braun, C., Hertel, F., Mustafa, O., Nordt, A., Pfeiffer, S. \& Peter, H.-U. (2014) Environmental assessment and management challenges of the Fildes Peninsula region. In: Antarctic Futures: Human Engagement with the Antarctic Environment, eds. T. Tin, D. Liggett, P.T. Maher \& M. Lamers, pp. 169-191. Dorsdrecht, the Netherlands: Springer.

Burek, C.V. \& Prosser, C.D., eds. (2008) The History of Geoconservation. Geological Society of London Special Publication, 300, p. 312. London, UK: Geological Society of London. 
Cockburn, H.A.P. \& Summerfield, M.A. (2004) Geomorphological applications of cosmogenic isotope analysis. Progress in Physical Geography 28: 1-42.

Crame, J.A., Francis, J.E., Cantrill, D.J. \& Pirrie, D. (2004) Maastrichtian stratigraphy of Antarctica. Cretaceous Research 25: 411-423.

Dingwall, P., Weighell, T. \& Badman, T. (2005) Geological world heritage: a global framework. A contribution to the global theme study of world heritage natural sites. Prepared by Protected Area Programme, IUCN/WCPA, p. 51. [www document]. URL http://whc.unesco.org/document/9777

Ellis, N.V., Bowen, D.Q., Campbell, S., Knill, J.L., McKirdy, A.P., Prosser, C.D., Vincent, M.A. \& Wilson, R.C.L. (1996) An Introduction to the Geological Conservation Reviem. Geological Conservation Review Series No. 1. p.131. Peterborough, UK: Joint Nature Conservancy Council.

Fang, A.M., Lui, X.H., Lee, J.I., Li, X.L. \& Huang, F.X. (2004) Sedimentary environments of the Cenozoic sedimentary debris found in the moraines of the Grove Mountains, east Antarctica and its climatic implications. Progress in Natural Science 14: 223 234.

Fogwill, C.J., Hein, A.S., Bentley, M.J. \& Sugden, D.E. (2012) Do blue-ice moraines in the Heritage Range show the West Antarctic ice sheet survived the last interglacial? Palaeogeography Palaeoclimatology Palaeoecology 335: 61-70.

Folco, L., Capra, A., Chiappini, M., Frezzotti, M., Mellini, M. \& Tabacco, I.E. (2002) The Frontier Mountain meteorite trap (Antarctica). Meteorites and Planetary Science 37: 209-228.

Francis, J.E., Pirrie, D. \& Crame, J.A., eds. (2006) Cretaceous - Tertiary high-latitude palaeoenvironments: Fames Ross Basin, Antarctica. Geological Society of London Special Publication, 258, p. 206. London, UK: Geological Society of London.

Fretwell, P.T., Hodgson, D.A., Watcham, E.P., Bentley, M.J. \& Roberts, S.J. (2010) Holocene isostatic uplift of the South Shetland Islands, Antarctic Peninsula, modelled from raised beaches. Quaternary Science Reviems 29: 1880-1893.

Gillies, J.A., Nickling, W.G. \& Tilson, M. (2009) Ventifacts and wind-abraded rock features in the Taylor Valley, Antarctica. Geomorphology 107: 149-160.

Glasser, N.F., Davies, B.J., Carrivick, J.L., Rodes, A., Hambrey, M.J., Smellie, J.L. \& Domack, E. (2014) Ice-stream initiation, duration and thinning on James Ross Island, northern Antarctic Peninsula. Quaternary Science Reviems 86: 78-88.

Gray, M. (2008) Geodiversity: the origin and evolution of a paradigm. In: The History of Geoconservation. Geological Society of London, Special Publication 300, eds. C.D. Burek \& C.D. Prosser, pp. 31-61. London, UK: Geological Society of London.

Grew, E. \& Carson, C. (2007) A treasure trove of minerals discovered in the Larsemann Hills. Australian Antarctic Magazine 13: $18-19$.

Grew, E.S., Armbruster, T., Medenbach, O., Yates, M.G. \& Carson, C.J. (2006) Stornesite-(Y),(Y,Ca)square Na$2(6)(\mathrm{Ca}, \mathrm{Na})(8)(\mathrm{Mg}, \mathrm{Fe})(43)(\mathrm{PO} 4)(36)$, the first terrestrial $\mathrm{Mg}-$ dominant member of the fillowite group, from granulite-facies paragneiss in the Larsemann Hills, Prydz Bay, East Antarctica. American Mineralogist 91: 1412-1424.

Harvey, R. (2003) The origin and significance of Antarctic meteorites. Chemie der Erde - Geochemistry 63: 93-147.

Houshold, I. \& Sharples, C. (2008) Geodiversity in the wilderness: a brief history of geoconservation in Tasmania. In: The History of Geoconservation. Geological Society of London, Special Publication 300, eds. C.D. Burek \& C.D. Prosser, pp. 257-272. London, UK: Geological Society of London.

Hughes, K.A., Fretwell, P., Rae, J., Holmes, K. \& Fleming, A. (2011) Untouched Antarctica: mapping a finite and diminishing environmental resource. Antarctic Science 23: 537-548.

Hughes, K.A., Pertierra, L.R. \& Walton, D.W.H. (2013) Area protection in Antarctica: how can conservation and scientific research goals be managed compatibly? Environmental Science and Policy 31: 120-132.

India (2010) Initial Environmental Evaluation for development of approach path at proposed new Indian Research Station at Larsemann Hills, East Antarctica. Information Paper 1. Antarctic Treaty Consultative Meeting XXXIII, Punta del Este, Uruguay, 3-14 May 2010.

Italy (2014) Initial Environmental Evaluation for the realization of a new access road to Enigma Lake Twin Otter Runway at Mario Zucchelli Station, Terra Nova Bay, Ross Sea, Antarctica. Information Paper 56. Antarctic Treaty Consultative Meeting XXXVII, Brasilia, Brazil, 28 April-7 May 2014.

JNCC (1977) Guidelines for Selection of Earth Science SSSIs. Joint Nature Conservancy Council (JNCC). [www document]. URL http://jncc.defra.gov.uk/page-2317

Johansson, C. E., ed. (2000) Geodiversitet $i$ Nordisk Naturvård. Copenhagen, Denmark: Nordisk Ministerråad.

Kennicutt, M.C., Klein, A.G., Montagna, P., Sweet, S., Wade, T., Palmer, T., Sericano, J. \& Denoux, G. (2010) Temporal and spatial patterns of anthropogenic disturbance at McMurdo Station, Antarctica. Environmental Research Letters 5(3): 304010.

Kong, P., Huang, F.K., Liu, X., Fink, D., Ding, L \& Lai, Q.Z. (2010) Late Miocene ice sheet elevation in the Grove Mountains, East Antarctica, inferred from cosmogenic Ne-21-Be-10-Al-26. Global and Planetary Change 72: 50-54.

Larwood, J.G. \& King, A.H. (2001) Conserving palaeontological sites: applying the principles of sustainable development. In: $A$ Future for Fossils. Cardiff National Museum of Wales, Geological Series No. 19, eds. M.G. Bassett, A.H. King, J.G. Larwood, N.A. Parkinson \& V.K. Deisler, pp. 119-125. Cardiff, Wales: Cardiff National Museum of Wales.

Larwood, J.G., Badman, T. \& McKeever, P.J. (2013) The progress and future of geoconservation at a global level. Proceedings of the Geologists'Association 124: 720-730.

NERC (1989) Proposed construction of airstrip at Rothera Point, Antarctica. Final Comprehensive Environmental Evaluation, p. 56. Swindon, UK: Natural Environment Research Centre (NERC).

Norway $(2014 a)$ Subsidiary Group on Management Plans - report on 2013/14 Intersessional Work. Attachment B: ASPA Stornes draft management plan. Working Paper 31. Antarctic Treaty Consultative Meeting XXXVII, Brasilia, Brazil, 28 April-7 May 2014.

Norway $(2014 b)$ Background and initial thoughts and questions: need for and development of procedures concerning ASPA and ASMA designation. Working Paper 33. Antarctic Treaty Consultative Meeting XXXVII, Brasilia, Brazil, 28 April-7 May 2014.

Pertierra, L.R. \& Hughes, K.A. (2013) Management of Antarctic Specially Protected Areas: permitting, visitation and information exchange practices. Antarctic Science 25: 553-564.

Prosser, C.D. (2013) Our rich and varied geoconservation portfolio: the foundation for the future. Proceedings of the Geologist's Association 124: 568-580. 
Prosser, C.D., Murphy, M. \& Larwood, J.G. (2006) Geological conservation: a guide to good practice. Peterborough, UK: English Nature. [www document]. URL http://publications. naturalengland.org.uk/publication/83048

Prosser, C.D., Burek, C.V., Evans, D.H., Gordon, J.E., Kirkbride, V.B., Rennie, A.F. \& Walmsley, C.A. (2010) Conserving geodiversity sites in a changing climate: managing challenges and responses. Geoheritage 2: 123-136.

Righter, K., Corrigan, C., McCoy, T. \& Harvey, R. (2014) 35 Seasons of U.S. Antartic Meteorites (1976-2010): a Pictorial Guide to the Collection. p. 360. Hoboken, New Jersey, USA: American Geophysical Union, John Wiley \& Sons.
Shaw, J.D., Terauds, A., Riddle, M.J., Possingham, H.P. \& Chown, S.L. (2014) Antarctica's protected areas are inadequate, unrepresentative, and at risk. PLoS Biology 12: e1001888.

Tin, T., Fleming, Z.L., Hughes, K.A., Ainley, D.G., Convey, P., Moreno, C.A., Pfeiffer, S., Scott, J. \& Snape, I. (2009) Impacts of local human activities on the Antarctic environment. Antarctic Science 21: 3-33.

UK, Argentina, Australia \& Spain (2014) The Antarctic Protected Area system: protection of outstanding geological features. Working Paper 35. Antarctic Treaty Consultative Meeting XXXVII, Brasilia, Brazil, 28 April-7 May 2014.

Yoshida, M. (2010) Discovery of the Yamato Meteorites in 1969. Polar Science 3: 272-284. 